\title{
Effects of daphnetin combined with Bcl2-siRNA on antiapoptotic genes in synovial fibroblasts of rats with collagen-induced arthritis
}

\author{
XIAOYING CHEN ${ }^{1,2^{*}}$, NANZHEN KUANG $^{1 *}$, XIAOPING ZENG ${ }^{1}$, \\ ZHIQIN ZHANG ${ }^{1}$, YANYAN LI ${ }^{1}$, WEI LIU ${ }^{1}$ and YINGYUAN FU ${ }^{1}$ \\ ${ }^{1}$ Department of Immunology, Medical College of Nanchang University, Nanchang, Jiangxi 330006; \\ ${ }^{2}$ Department of Clinical Laboratory, Children's Hospital of Jiangxi, Nanchang, Jiangxi 330029, P.R. China
}

Received June 1, 2016; Accepted July 21, 2017

DOI: $10.3892 / \mathrm{mmr} .2017 .8008$

\begin{abstract}
The aim of the present study was to investigate the effects of daphnetin combined with B cell lymphoma 2 (Bcl2)-targeted small interfering (si)RNA (si-Bcl2) on antiapoptotic genes in fibroblast-like synoviocytes (FLS) in rats with collagen II-induced arthritis (CIA). The roles of si-Bcl2 and daphnetin were determined by measuring the expression levels of $\mathrm{Bcl} 2$. Protein and mRNA expression levels of $\mathrm{Bcl} 2$ in FLS were determined by flow cytometry and reverse transcription-quantitative polymerase chain reaction. Apoptosis of FLS was also determined by flow cytometry. It was revealed that treatment with si-Bcl 2 or daphnetin alone resulted in downregulation of Bcl 2 mRNA and protein expression. In addition, the mRNA expression levels of the signal transducer and activator of transcription 3 (STAT3), which transcriptionally regulates the activity of mitochondria, were reduced. The combination of si-Bcl2 and daphnetin exhibited an enhanced effect on rheumatoid arthritis FLS (RAFLS), in which the apoptotic rate was significantly higher than either treatment alone. The results suggested that si-Bcl combined with daphnetin may have an enhanced effect in promoting apoptosis of RAFLS derived from CIA rats, and a possible underlying molecular mechanism may function through the downregulation of $\mathrm{Bcl} 2$ expression and STAT3, which is located upstream of $\mathrm{Bcl} 2$ in the mitochondrial apoptotic pathway. The results of the present study are expected to provide theoretical and experimental basis for the treatment of RA and the medicinal development of daphnetin combined siRNA.
\end{abstract}

Correspondence to: Professor Yingyuan $\mathrm{Fu}$, Department of Immunology, Medical College of Nanchang University, 461 Nanchang Bayi Road, Nanchang, Jiangxi 330006, P.R. China E-mail: yingyuan1954@163.com

*Contributed equally

Key words: B cell lymphoma-2 short interfering RNA, daphnetin, fibroblast-like synoviocytes, collagen-induced arthritis rats

\section{Introduction}

Rheumatoid arthritis (RA) is a systemic autoimmune disease that is characterized by chronic joint inflammation, synovial hyperplasia and the progressive destruction of cartilage and bone $(1,2)$. It has been revealed that a primary manifestation in RA is the excessive proliferation of RA fibroblast-like synoviocytes (RAFLS) $(3,4)$, which may be closely associated with impaired RAFLS apoptosis $(5,6)$, which is believed to be a result of overexpression of the antiapoptotic gene B cell lymphoma 2 ( $\mathrm{Bcl} 2)(7,8)$. Therefore, the downregulation of $\mathrm{Bcl} 2$ expression to increase RAFLS apoptosis may be a promising therapeutic option for the treatment of RA (9).

Daphnetin, an active ingredient extracted from Daphne odora var. marginata, possesses many biological and medical properties, including antiparasitic, anti-inflammatory and analgesic properties (10). Daphnetin may also kill aphids, inhibit protein kinases and improve abnormal blood rheology of type 2 diabetic rats (11). Results from our preliminary study performed in 2011 revealed that daphnetin may have therapeutic and immunomodulatory effects in rats with collagen II-induced arthritis (CIA) (12). In 2012, it was demonstrated that the apoptosis rate of RAFLS was elevated upon treatment with daphnetin (13).

RNA interference (RNAi) is a gene silencing technology. RNAi has been widely used for the anti-inflammatory treatment of RA in a number of studies worldwide (14-18). The results of these studies have revealed that RNAi is a promising therapeutic option for RA. However, RNAi targeting of antiapoptotic genes has not yet been reported in RA.

In the present study, Bcl2-targeted small interfering (si)RNA (si-Bcl2) was synthesized and transfected into RAFLS using a liposome-mediated method. si-Bcl2 treatment was demonstrated to successfully interfere with the expression of Bcl2. Subsequently, RAFLS were treated with daphnetin, and the apoptotic rate was measured, along with the mRNA expression levels of $\mathrm{Bcl} 2$ and signal transducer and activator of transcription 3 (STAT3). In addition, the possible underlying mechanism by which daphnetin combined with si-Bcl2 affects antiapoptotic gene expression in the RAFLS of CIA rats was investigated. The present study is expected to make a new contribution to the treatment of RA. 


\section{Materials and methods}

Materials. FLS from CIA rats and healthy rats were purchased from Shanghai Institute of Health Industry Co., Ltd. (Shanghai, China). Daphnetin, extracted from Daphne odora var. marginata by high-speed counter-current chromatography, was purchased from Shanghai Yuanye Biotechnology Co., Ltd. (Shanghai, China). Other reagents were purchased as follows: Lipofectamine ${ }^{\circledR} 2000$ (Invitrogen; Thermo Fisher Scientific, Inc., Waltham, MA, USA); siRNAs (Ribobio Co., Ltd., Guangzhou, China); Opti-MEM I (Invitrogen; Thermo Fisher Scientific, Inc., Waltham, MA, USA); reverse transcription-quantitative polymerase chain reaction (RT-qPCR) primers (Sangon Biotech Co., Ltd., Shanghai, China); ReverTra Ace qPCR RT kit (Toyobo Life Science, Osaka, Japan); SYBR Green Real Time PCR Master mix (Toyobo Life Science); rabbit anti-Bcl2 antibody conjugated to fluorescein isothiocyanate (FITC; bs0032r-F; Beijing Biosynthesis Biotechnology Co., Ltd., Beijing, China); annexin V/propidium iodide (PI) kit (KeyGen Biotechology Co. Ltd., Nanjing, China); diethyl pyrocarbonate (Sigma-Aldrich; Merck KGaA, Darmstadt, Germany); and TransZol (Beijing TransGen Biotech Co., Ltd., Beijing, China).

Cultured FLS from CIA rats. FLS were cultured and passaged in Dulbecco's Modified Eagle's medium (DMEM) supplemented with penicillin $(100 \mathrm{U} / \mathrm{ml})$, streptomycin $(100 \mu \mathrm{g} / \mathrm{ml})$ and $10 \%$ foetal bovine serum (FBS, Tianjin Haoyang Biological Manufacture Co., Ltd., Tianjin, China). All cultures were incubated at $37^{\circ} \mathrm{C}$ in $5 \%$ humidified $\mathrm{CO}_{2}$. Following 2 days incubation, FLS were digested using $0.25 \%$ trypsin prior to centrifugation at low speed $(112 \mathrm{x}$ g for $10 \mathrm{~min}$ at $25^{\circ} \mathrm{C}$ ). Nonadherent granulocytes were removed, and FLS were cultured in 24 -or 6 -well plates $\left(5 \times 10^{4}\right.$ or $1 \times 10^{5}$ cells $\left./ \mathrm{ml}\right)$ in $500 \mu \mathrm{l}$ or $2 \mathrm{ml} \mathrm{DMEM}$, respectively, containing $10 \% \mathrm{FBS}$ without penicillin and streptomycin for $24 \mathrm{~h}$ following treatment with siRNA (various concentrations) or daphnetin $\left(40 \mu \mathrm{g} / \mathrm{ml}, 37^{\circ} \mathrm{C}\right)$.

siRNA synthesis and transfection. All siRNA sequences were purchased from Ribobio Co., Ltd. (Guangzhou, China). A total of three siRNA sequences specific to $\mathrm{Bcl} 2$ were selected: i) si-Bcl2.1, GCCUCCGACCCUACGGAAA; ii) siBcl2.2, CCUACUGACUCAUGGACUU; and iii) siBcl2.3, CCUCUU GUCCCAUACUAUU. siRNAs were chemically synthesised and annealed by Nanjing Anbo Ruila Biotechnology Co., Ltd. Three targeting siRNA was respectively used to silence the $\mathrm{Bcl} 2$ gene in FLS of CIA rats. siRNAs labelled with fluorescent cyanine 3 (Cy3; siN05815122149; Ribobio Co., Ltd.) were used to test whether the transfection was successful. An siRNA specific to an invalid gene (siN05815122147; Ribobio Co., Ltd.) was used as a negative silencing control. Experimental groups were used to determine the optimal siRNA concentration, including siRNA transfection negative control group (NC group), si-Bcl2.1-transfection group, si-Bcl2.2-transfected group and si-Bcl2.3-transfection group.

Transfection was conducted according to the manufacturer's protocol. Briefly, $50 \mu \mathrm{l}$ Opti-Mem I (serum-free, penicillin-free and streptomycin-free) was used in 24-well plates (or $250 \mu 1$ in 6 -well plates) to dilute $5,2.5,1.25,0.75$,
0.5 and $0.25 \mu 1$ annealed siRNA (or 20, 10, 5, 3, 2 and $1 \mu 1$ siRNA in 6-well plates). Another $50 \mu$ l Opti-Mem I was used in 24-well plates (or $250 \mu \mathrm{l}$ in 6-well plates) to dilute $1 \mu 1$ Lipofectamine 2000 (or $5 \mu \mathrm{l}$ in 6-well plates). Subsequently, the diluted siRNA-Lipofectamine 2000 complex was incubated at room temperature for $20 \mathrm{~min}$. This mixture was then added to $400 \mu \mathrm{l}$ FLS cell culture in 24 -well plates ( $5 \times 10^{4}$ cells/well), or $1,500 \mu \mathrm{l}$ in 6 -well plates $\left(1 \times 10^{5}\right.$ cells/well). A concentration gradient of the siRNA was generated as follows: 200, 100, 50, 30, 20 and $10 \mathrm{nM}$. Following $6 \mathrm{~h}$ incubation at $37^{\circ} \mathrm{C}$, an equal volume of DMEM supplemented with $10 \%$ FBS was added to the cells. When combined with siRNA, daphnetin (final concentration $40 \mu \mathrm{g} / \mathrm{ml}$ ) was added to the FLS cell culture as appropriate for each of the treatment groups. Following 24 or $48 \mathrm{~h}$ transfection at $37^{\circ} \mathrm{C}, \mathrm{Cy} 3$ fluorescence was observed under a fluorescent microscope to confirm that the transfection was successful. The transfected RAFLS were washed with DMEM and then immediately used for subsequent experiments.

Combined treatment of CIA rat FLS cells with daphnetin and $s i$ - $B c l 2$. Experimental groups were: i) FLS of untreated healthy Wistar rats (healthy group); ii) untreated FLS of CIA rats (CIA group); iii) daphnetin (40 $\mu \mathrm{g} / \mathrm{ml})$-treated group (E003 group); iv) si-Bcl2-treated group; v) daphnetin (40 $\mu \mathrm{g} / \mathrm{ml})$ plus si-Bcl2 combined treatment group (E003-B group). Each group of cells was treated by the method of siRNA transfection as described above. Following treatment $\left(5 \times 10^{4} / 1 \times 10^{5}\right.$ cells/well at $37^{\circ} \mathrm{C}$ in $5 \%$ humidified $\mathrm{CO}_{2}$ ), FLS were cultured for 24,48 and $72 \mathrm{~h}$, and total RNA was extracted to measure the relative mRNA expression levels of $\mathrm{Bcl} 2$ and STAT3. In addition, resuspended FLS were used to measure $\mathrm{Bcl} 2$ protein expression levels and to assess apoptosis by flow cytometry.

Total RNA extraction and reverse transcription. Total RNA was isolated from FLS ( $5 \times 10^{4}$ cells) following gene silencing using TRIzol (All-in gold Biological Co., Ltd.), according to the manufacturer's protocol. cDNA was synthesized using the ReverTra Ace qPCR RT kit (Toyobo Life Science, Osaka, Japan) was used. Briefly, extracted RNA was heat denatured at $65^{\circ} \mathrm{C}$ for $5 \mathrm{~min}$ and immediately cooled on ice. Subsequently, $1 \mu 1$ RT Enzyme mix, $1 \mu$ l Primer mix and $4 \mu 1$ 5X RT buffer were incubated with $1 \mu \mathrm{g}$ DNA-free total RNA for $15 \mathrm{~min}$ at $37^{\circ} \mathrm{C}$. The mixture was incubated for $5 \mathrm{~min}$ at $98^{\circ} \mathrm{C}$ to inactivate the RT enzyme, and the first-strand cDNA was stored at $4^{\circ} \mathrm{C}$ until use in qPCR.

$R T-q P C R$. For $q \mathrm{PCR}$, reactions were performed in a volume of $20 \mu \mathrm{l} \mathrm{SYBR-Green} \mathrm{Real} \mathrm{Time} \mathrm{PCR} \mathrm{Master} \mathrm{mix} \mathrm{(Toyobo}$ Life Science). The primers used in this study were as follows: Bcl2, forward 5'-GGGATGCCTTTGTGGAACTAT-3, reverse 5'-AGGTATGCACCCAGAGTGATG-3' (124 bp); STAT3, forward 5'-GGGCACAAACACAAAAGTGAT-3', reverse 5'-CAGTCACAATCAGGGAAGCAT-3' (140 bp); $\beta$-actin, forward 5'-TGACAGGATGCAGAAGGAGA-3', reverse 5'-TAGAGCCACCAATCCACACA-3' (106 bp). Thermocycling conditions included initial denaturation at $95^{\circ} \mathrm{C}$ for $1 \mathrm{~min}$, followed by 40 cycles of denaturation at $95^{\circ} \mathrm{C}$ for $15 \mathrm{sec}$, annealing at $60^{\circ} \mathrm{C}$ for $15 \mathrm{sec}$ and extension at $72^{\circ} \mathrm{C}$ for $45 \mathrm{sec}$. qPCR was performed on an ABI 7500 PCR instrument. A relative quantitative assay was adopted (19), 
A
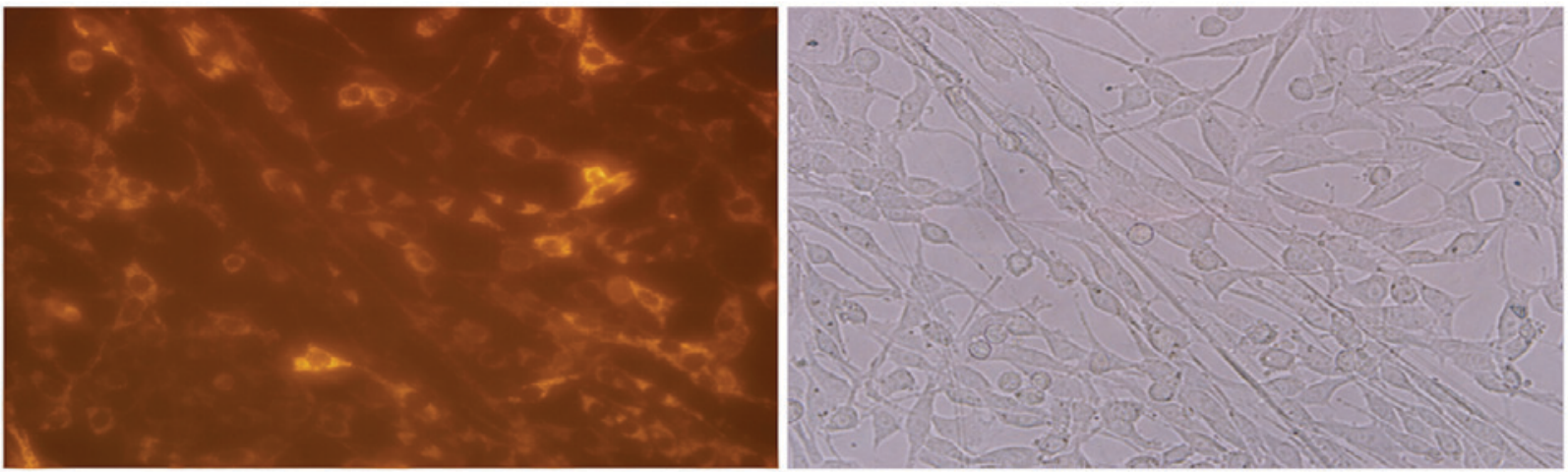

B
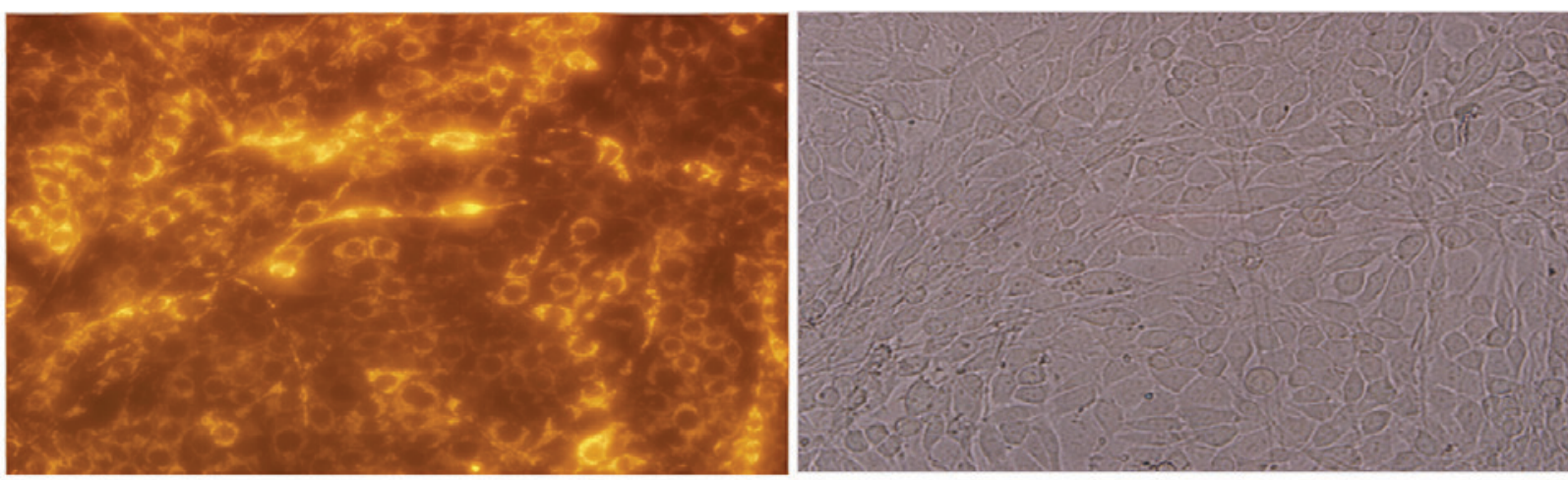

Figure 1. Observation of fluorescence. The optimal siRNA was selected, and FLS were transfected with Cy3-labelled siRNA to test whether the transfection was successful. Magnification, x400 (A) Following 24 h incubation, orange fluorescence was observed by an inverted fluorescence microscope. (B) Orange fluorescence from FLS cells transfected with Cy3-labeled siRNA following $48 \mathrm{~h}$ incubation. Right hand images are non-fluorescent for comparison. Bcl2, B cell lymphoma 2; Cy3, cyanine 3; FLS, fibroblast-like synoviocytes; siRNA, short interfering RNA.

and the melting curve increased following amplification. The reference gene $\beta$-actin, and Bcl 2 and STAT3 were simultaneously amplified in the samples of each experimental group. Each sample was tested in triplicate. Samples were obtained from $\geq 3$ independent experiments to calculate the mean and standard deviation. The formula $2^{-\Delta \Delta \mathrm{Cq}}$ was used to calculate the relative expression of Bcl-2, STAT3mRNA (19).

Flow cytometry. $\mathrm{Bcl} 2$ protein expression analysis and the apoptotic rate of FLS from CIA rats were performed on a FACScan flow cytometer (BD Biosciences, Franklin Lakes, NJ, USA). For the Bcl2 protein, a FITC-conjugated rabbit anti-rat Bcl2 antibody (Biosynthesis Corporation, Beijing, China) was used. FLS cells (1x10 cells/well) were treated as aforementioned, collected by trypsinization following $72 \mathrm{~h}$ incubation, fixed by $1 \%$ paraformaldehyde at room temperature for $15 \mathrm{~min}$, and resuspended with $100 \mu \mathrm{l}$ or $500 \mu \mathrm{l}$ PBS. Following collection, cells were stained with (FITC)-labeled rabbit anti-rat Bcl2 antibody (1:100) and 70\% ethanol added in the dark for $15 \mathrm{~min}$ at room temperature for permeabilisation. Bcl2 protein expression was assessed by determining the average fluorescence intensity. Apoptosis of FLS was examined using a FITC-labeled Annexin V/propidium iodide (PI) Apoptosis Detection kit (Nanjing KeyGen Biotechology Co. Ltd., Nanjing, China) according to the manufacture's protocol. Cells $\left(1 \times 10^{5}\right.$ cells/well) treated as aforementioned for $72 \mathrm{~h}$ were collected by trypsinization, fixed by $70 \%$ ethanol in the dark for $15 \mathrm{~min}$ at $4^{\circ} \mathrm{C}$ and washed twice with PBS. The cells were resuspended in $500 \mu \mathrm{l}$ binding buffer. Then $5 \mu \mathrm{l}$ Annexin-V-FITC and $5 \mu \mathrm{l}$ PI-FITC were added and incubated in the dark for $30 \mathrm{~min}$ at room temperature. Data acquisition and analysis were performed in a Becton Dickinson FACSCalibur flow cytometer using Cell Quest software version 6.1.2 (BD Biosciences, Franklin Lakes, NJ, USA).

Statistical analysis. All data are expressed as the mean \pm standard deviation, and were analysed by one-way analysis of variance followed by LSD post hoc multiple comparison test using SPSS version 19.0 software (IBM Corp., Armonk, NY, USA). A Student's t-test was used to determine the significances of differences in multiple comparisons. $\mathrm{P}<0.05$ was considered to indicate a statistically significant difference.

\section{Results}

Cy3-labeled siRNA transfection efficiency of FLS. Cy3-labeled si-Bcl2 was transfected into FLS. To determine whether the transfection was successful, the fluorescence was observed under a microscope at 24 and $48 \mathrm{~h}$ post-transfection (Fig. 1A and $\mathrm{B}$, respectively).

Optimisation of experimental conditions. Identification of the optimal siRNA concentration and incubation time was examined, as well as determining the optimal treatment time for daphnetin. All experimental conditions were designed to assess the mRNA expression levels of the antiapoptotic gene $\mathrm{Bcl} 2$, which was determined using RT-qPCR. The results revealed that $\mathrm{Bcl} 2$ mRNA expression in the si-Bcl2.1 group was significantly lower compared with the $\mathrm{NC}$, si-Bcl2.2, and si-Bcl2.3 groups (Fig. 2A). As demonstrated in Fig. 2B, $100 \mathrm{nM}$ 
si-Bcl2.1 inhibited Bcl2 mRNA expression most following transfection for $48 \mathrm{~h}$ compared with the NC group (Fig. 2B). In a previous study, it was determined that $40 \mu \mathrm{g} / \mathrm{ml}$ daphnetin significantly promoted FLS apoptosis (13). Therefore, the present study focused on determining the most suitable length of time required to downregulate $\mathrm{Bcl} 2$ mRNA expression. The results demonstrated that $\mathrm{Bcl} 2$ mRNA expression in FLS cells following daphnetin treatment for 48 or $72 \mathrm{~h}$ was significantly lower compared with cells treated for $24 \mathrm{~h}$ and untreated CIA FLS cells (Fig. 2C). However, daphnetin treatment for $48 \mathrm{~h}$ was not statistically significant $(\mathrm{P}>0.05)$ compared with for $72 \mathrm{~h}$, so cells were treated for 48 and $72 \mathrm{~h}$ to observe $\mathrm{Bcl} 2$ mRNA expression in the later combined experiment.

Influence of daphnetin combined with si-Bcl2 on mRNA and protein expression of Bcl2 and $m R N A$ expression of STAT3 in RAFLS derived from CIA rats. In the optimal conditions, si-Bcl2.1 was transfected into FLS and daphnetin was added to FLS cultures $6 \mathrm{~h}$ following gene silencing. $\mathrm{Bcl} 2$ and STAT3 mRNA expression levels were determined by RT-qPCR (Fig. 3A and B, respectively). Bcl2 protein expression was assessed by determining the average fluorescence intensity using flow cytometry (Fig. 3C). The results demonstrated that Bcl 2 mRNA expression in the E003-B group was significantly lower than that in the other treatment groups. In addition, $\mathrm{Bcl} 2 \mathrm{mRNA}$ expression in the E003-B group treated for $48 \mathrm{~h}$ was significantly lower compared with that in the same group treated for $72 \mathrm{~h}(\mathrm{P}<0.05)$, and no significant difference was observed in expression between the E003-B group treated for $48 \mathrm{~h}$ and the healthy group treated for $48 \mathrm{~h}$ ( $\mathrm{P}>0.05$; Fig. 3A). It suggested that daphnetin combined with si-Bcl2 for the treatment of RA was effective, particularly as in the treatment for $48 \mathrm{~h}, \mathrm{Bcl} 2 \mathrm{mRNA}$ was downregulated most. Consistent with Bcl 2 mRNA expression, STAT3 mRNA expression in the E003-B group was also decreased compared with the other treatment groups $(\mathrm{P}<0.05$; Fig. $3 \mathrm{~B})$. $\mathrm{Bcl} 2$ protein expression in the E003-B group was significantly lower compared with expression in the other treatment groups and the CIA group $(\mathrm{P}<0.05$; Fig. 3C).

Effects of daphnetin combined with si-Bcl2 on apoptosis of RAFLS derived from CIA rats. The apoptotic rate of RAFLS derived from CIA rats was also determined by flow cytometry. The results demonstrated that the apoptotic rate of FLS in the E003-B group was significantly higher than that of other groups $(\mathrm{P}<0.05$; Fig. 4).

\section{Discussion}

RA is a common systemic autoimmune disease that is characterised by chronic joint inflammation, synovial hyperplasia and progressive destruction of cartilage and bone. This process is sustained and recurs so that the affected joints swell and lose functionality. If RA is not treated in a timely manner, it may result in severe joint deformity, leading to multiple joint dysfunction and other organ diseases. RA and complications caused by RA, such as cancer $(20,21)$, are a major cause of disability or lost labour in China. However, the pathogenesis of RA remains to be elucidated. Recently, studies have revealed that RA may be associated with an abnormal autoimmune
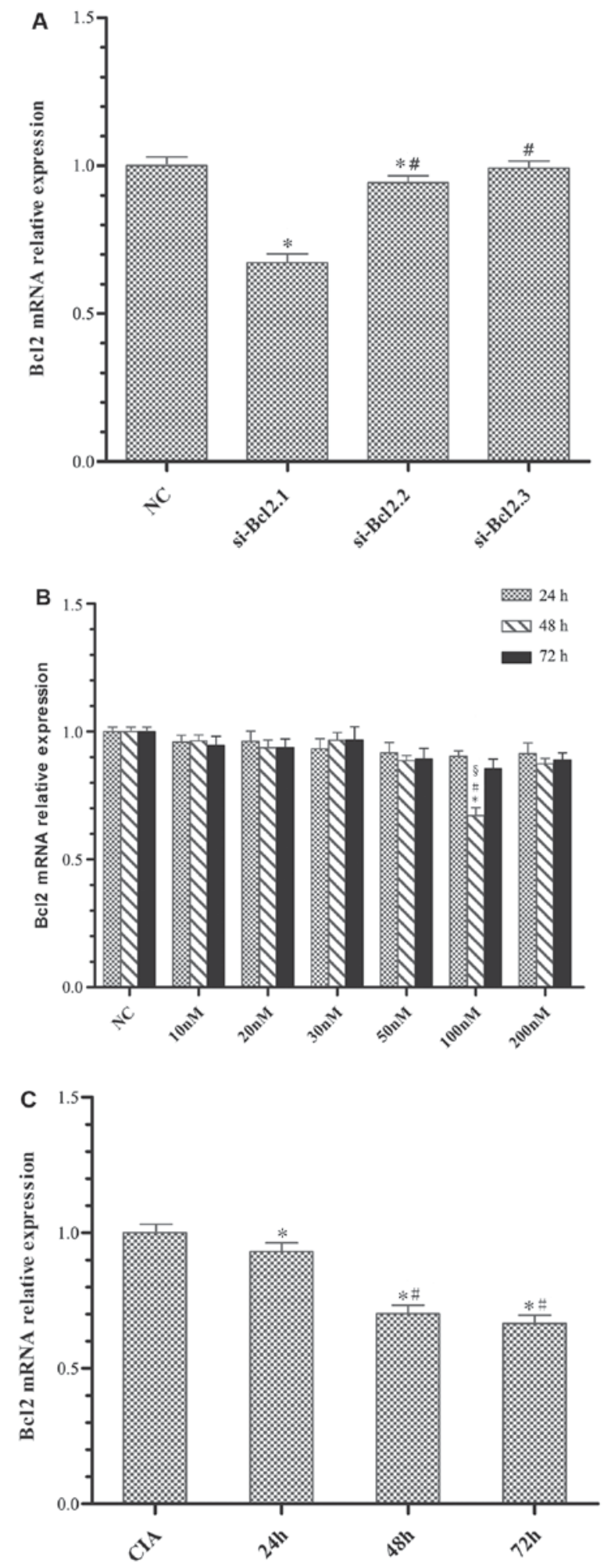

Figure 2. Optimization of experimental conditions. (A) si-Bcl2.1, si-Bcl2.2 or si-Bcl2.3 (100 nM) was transfected into FLS. Reverse transcription-quantitative polymerase chain reaction was performed using primers specific to $\mathrm{Bcl} 2$ and $\beta$-actin, and relative quantification of gene expression was performed by the $2^{-\triangle \Delta C q}$ method. ${ }^{*} \mathrm{P}<0.05$ vs. NC group; ${ }^{\#} \mathrm{P}<0.05$ vs. si- $\mathrm{Bcl} 2.1$ group; (B) Dilution curve of si-Bcl2.1 to identify the optimal siRNA concentration and incubation duration that significantly reduced mRNA expression levels of $\mathrm{Bcl} 2$. ${ }^{*} \mathrm{P}<0.05$ vs. NC group; ${ }^{\text {}} \mathrm{P}<0.05$ vs. $24 \mathrm{~h}$ group at the same concentration; ${ }^{\circledR} \mathrm{P}<0.05$ vs. $72 \mathrm{~h}$ group at the same concentration. (C) FLS were treated with E003 $(40 \mu \mathrm{g} / \mathrm{ml})$ for 24, 48 and $72 \mathrm{~h}$. The effects of E003 were assessed by determining $\mathrm{Bcl} 2$ mRNA expression levels. ${ }^{*} \mathrm{P}<0.05$ vs. CIA group; ${ }^{\#} \mathrm{P}<0.05$ vs. 24 h group. Bcl2, B cell lymphoma 2; CIA, collagen II-induced arthritis; E003, daphnetin; FLS, fibroblast-like synoviocytes; NC, negative control; si-Bcl2, short interfering RNA targeting Bcl2. 

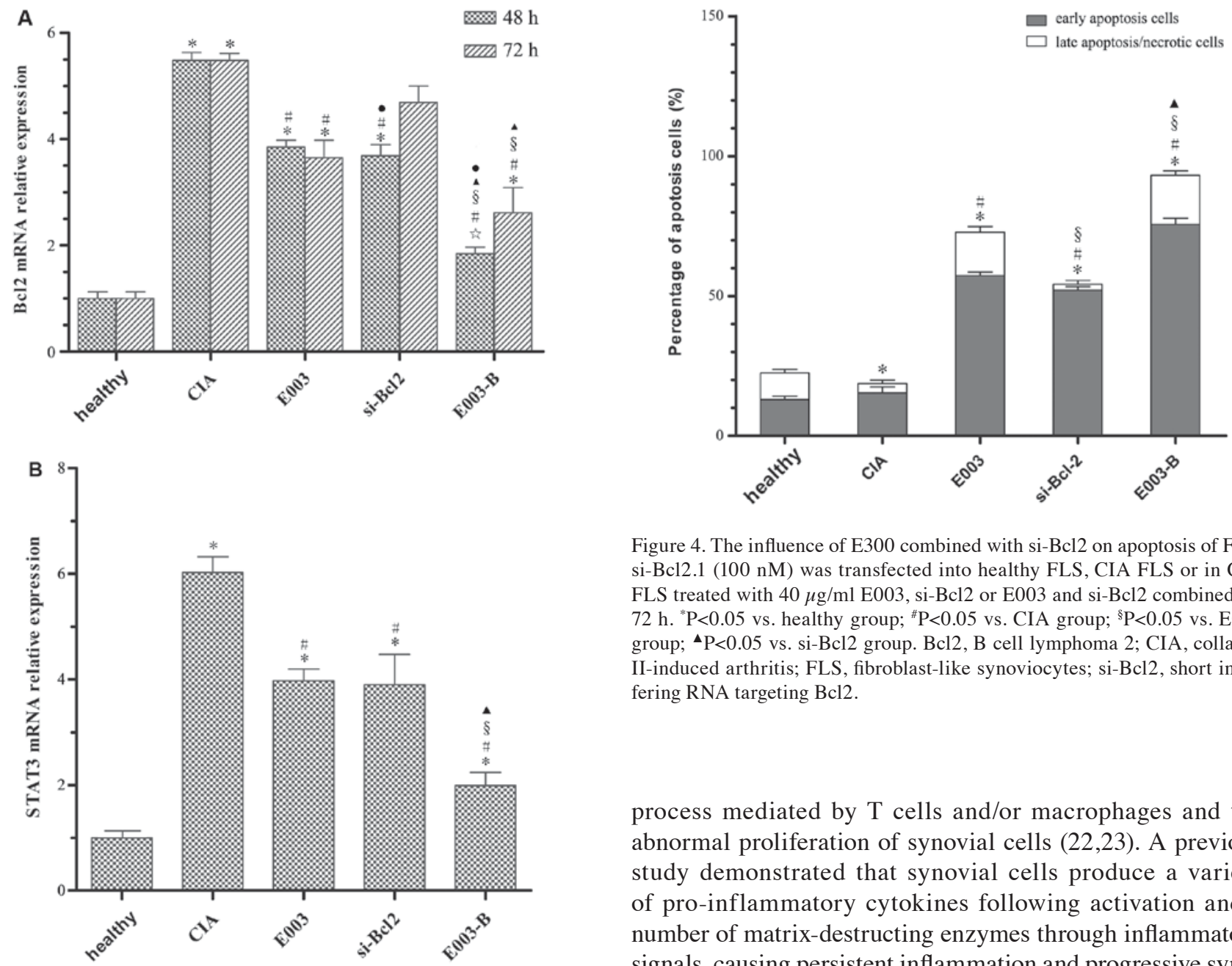

Figure 4. The influence of E300 combined with si-Bcl2 on apoptosis of FLS. si-Bcl2.1 $(100 \mathrm{nM})$ was transfected into healthy FLS, CIA FLS or in CIA FLS treated with $40 \mu \mathrm{g} / \mathrm{ml} \mathrm{E003,} \mathrm{si-Bcl} 2$ or E003 and si-Bcl 2 combined for $72 \mathrm{~h} .{ }^{*} \mathrm{P}<0.05$ vs. healthy group; ${ }^{\# \mathrm{P}}<0.05$ vs. CIA group; ${ }^{\S} \mathrm{P}<0.05$ vs. E003 group; ${ }^{\wedge} \mathrm{P}<0.05$ vs. si-Bcl2 group. Bcl2, B cell lymphoma 2; CIA, collagen II-induced arthritis; FLS, fibroblast-like synoviocytes; si-Bcl2, short interfering RNA targeting Bcl2.

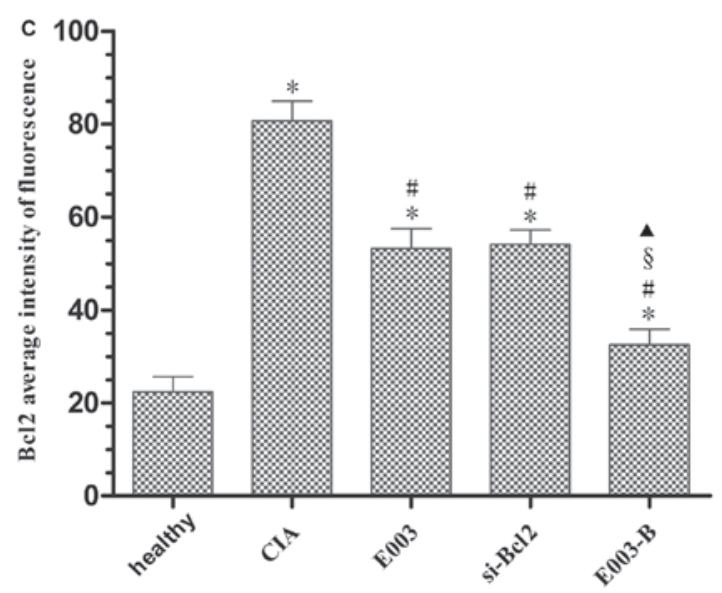

Figure 3. Influence of E300 combined with si-Bcl2 on the gene encoding antiapoptotic $\mathrm{Bcl} 2$ and the signalling protein STAT3. (A) mRNA expression levels of $\mathrm{Bcl} 2$ in healthy FLS, CIA FLS or CIA FLS treated with E003, si-Bcl2 or E003-B. $100 \mathrm{nM}$ si-Bcl2.1 was transfected into FLS for $48 \mathrm{~h}$ and $40 \mu \mathrm{g} / \mathrm{ml} \mathrm{E003} \mathrm{was} \mathrm{cultured} \mathrm{together} \mathrm{with} \mathrm{FLS} \mathrm{for} 72 \mathrm{~h}$. Owing to the different periods of time required for si-Bcl2 and E003 to affect Bcl2 mRNA expression in FLS, mRNA expression of Bcl2 was measured after the cells had been incubated with both agents for 48 and $72 \mathrm{~h}$. (B) STAT3 mRNA expression was determined following treatment of FLS for $72 \mathrm{~h}$. (C) Bcl2 protein expression was detected by flow cytometry, also following treatment of FLS for $72 \mathrm{~h}$. Cells in all groups were treated as in section 2 for 72 h. ${ }^{\text {"}} \mathrm{P}>0.05$ vs. healthy group; ${ }^{*} \mathrm{P}<0.05$ vs. healthy group ${ }^{\text {" }} \mathrm{P}<0.05$ vs. CIA group; ${ }^{\circledR} \mathrm{P}<0.05$ vs. E003 group; ${ }^{\wedge} \mathrm{P}<0.05$ vs. si-Bcl 2 group; ${ }^{\bullet} \mathrm{P}<0.05$ vs. $72 \mathrm{~h}$ group. Bcl2, B cell lymphoma 2; CIA, collagen II-induced arthritis; E003, daphnetin; FLS, fibroblast-like synoviocytes; si-Bcl2, short interfering RNA targeting Bcl2; STAT3, signal transducer and activator of transcription 3.

process mediated by $\mathrm{T}$ cells and/or macrophages and the abnormal proliferation of synovial cells $(22,23)$. A previous study demonstrated that synovial cells produce a variety of pro-inflammatory cytokines following activation and a number of matrix-destructing enzymes through inflammatory signals, causing persistent inflammation and progressive synovial tissue destruction in RA patients (24). It is now considered that FLS cells do not only fill space, but they are also directly responsible for cartilage destruction and drive both inflammation and autoimmunity. Active RAFLS cells stimulate the expression of proinflammatory cytokines, such as interleukin (IL)-8 and IL-6, and also form a complex that constantly changes the expression levels of various molecules without external stimulation by altering the expression of regulatory factors, signalling molecules and apoptosis-associated molecules $(25,26)$. RAFLS cells, which are characterised by incomplete conversion, exhibit tumour-like proliferation with sustained activation, although they may escape from the inflammatory environment and have strong invasive properties (27), and this is closely associated with impaired apoptosis of RAFLS. Impaired apoptosis prolongs the life of RAFLS, causing joint cartilage and bone destruction (28).

In the clinic, many diseases are associated with impaired apoptosis of lesion cells. FLS cells in RA are tumour-like proliferation (27). The induction of cell apoptosis is an efficient strategy with which to inhibit proliferation. Inducing the apoptotic pathway with active ingredients in Chinese medicine has become a popular target for inhibition of tumour or tumour-like growth. The present study used daphnetin extracted from natural $D$. odora, which has many pharmacological applications, such as anti-inflammatory, analgesic, antitumoural and immune regulatory properties (29-32). A previous study by the authors of the present study demonstrated that daphnetin not only inhibited immunised foot swelling and inflammation 
but also relieved the degeneration of articular chondrocytes, increased the number of forkhead box $\mathrm{P}^{+}$regulatory $\mathrm{T}$ cells and regulated $\mathrm{T}$ helper 17 cells to achieve immune balance in CIA (33). In 2012, it was also demonstrated that daphnetin treatment demethylated the apoptosis genes death receptor 3 , programmed cell death 5, Fas ligand and the promoter region of p53 in CIA (13).

RNAi-associated RNA silencing pathways constitute a group of small-RNA-based silencing mechanisms that is conserved in eukaryotic cells and affect their whole existence (34). RNA silencing requires a number of enzymes, and different species require different enzymes, generally including argonaute (which binds to siRNA), and P-element induced wimpy testis protein (35). RNAi is an efficient sequence-specific gene knockout technology that has been rapidly developed for applications in infectious diseases and gene therapy areas of cancer. It may be a novel idea that an efficient siRNA may be used to treat RA alone or in combination with biological agents or other medicines. However, studies have focused on using RNAi for anti-inflammation-based treatments of RA $(36,37)$. The use of RNAi to remove or turn off specific genes highly expressed in RAFLS, such as the antiapoptosis protein $\mathrm{Bcl} 2$, has not been previously reported. The present study investigated the ability of combined treatment with a Bcl2-specific RNAi with daphnetin, an active ingredient of traditional Chinese medicine, to downregulate antiapoptosis gene expression, aiming to promote RAFLS apoptosis and reduce the over-proliferation of these cells.

In the present study, daphnetin was combined with si-Bcl2 to explore the effect of this combined treatment on antiapoptotic gene expression and the underlying molecular mechanism of RAFLS of CIA rats. Bcl 2 exerts an antiapoptotic effect by blocking common signalling pathways of apoptosis. Previous studies have demonstrated that $\mathrm{Bcl} 2$ gene expression is significantly higher in the synovial tissue of RA patients and that it inhibits apoptosis by preventing cytochrome $\mathrm{C}$ (Cyto $\mathrm{C}$ ) release from mitochondria and also by regulating caspase activity following Cyto $\mathrm{C}$ release (38). A report by Ferdek et al (39) revealed that $\mathrm{Bcl} 2$ serves important roles in $\mathrm{Ca}^{2+}$ signalling by influencing inositol triphosphate receptors and regulating $\mathrm{Ca}^{2+}$-induced $\mathrm{Ca}^{2+}$ release. In the present study, it was demonstrated that $\mathrm{Bcl} 2$ was highly expressed in synovial cells in CIA rats, and treatment with daphnetin or $\mathrm{si}-\mathrm{Bcl} 2$ alone resulted in mRNA and protein expression levels that were significantly lower than those in the CIA group. There was clear synergy between daphnetin and si-Bcl 2 in downregulating $\mathrm{Bcl} 2$ mRNA and protein expression levels.

Apoptosis is initiated by environmental stimuli and induces a variety of other gene regulation mechanisms. It serves an important role in eliminating cells that have aged in the body or have the potential for uncontrolled growth, and also maintains homeostasis of organs. The antiapoptotic gene $\mathrm{Bcl} 2$ is primarily involved in the mitochondrial pathway and endoplasmic reticulum pathway. STAT3, an important member of the STAT family, is commonly expressed in human tumours and is widely involved in many processes, such as tumour invasion and metastasis, angiogenesis, apoptosis resistance and immune evasion. STAT3, located upstream of $\mathrm{Bcl} 2$ gene regulation in many apoptotic signalling pathways, may regulate the expression of $\mathrm{Bcl} 2$ to block apoptosis. Li et al (40) reported that downregulation of STAT3 expression using RNAi significantly reduced $\mathrm{Bcl} 2$ and cyclin D expression and thereby induced glioblastoma stem cell apoptosis and inhibited cell growth. Lee et al (41) demonstrated that STAT3-mediated IL-17 expression induces the upregulation of $\mathrm{Bcl} 2$ expression, and IL-17 promotes proliferation of RAFLS through the STAT3 apoptosis pathway. In the present study, it was revealed that the apoptosis of FLS cells increased with daphnetin treatment alone or with si-Bcl 2 treatment alone. In the mitochondrial apoptotic signalling pathway, there was a corresponding decline in STAT3 expression, and there was also an enhanced association between daphnetin and si-Bcl2 in downregulating STAT3 expression.

The results of the present study suggested that there may be an interaction between daphnetin and si-Bcl2 in reducing the expression levels of $\mathrm{Bcl} 2$ and STAT3, which promoted FLS apoptosis in CIA rats. The effects of daphnetin combined with sibcl-2 in the present study may provide a new direction for the treatment of RA. However, the mechanism of these effects on FLS in RA remains to be elucidated.

\section{Acknowledgements}

The authors would like to thank Chuan Liu and Qiong $\mathrm{Wu}$ at the Second Affiliated Hospital of Nanchang University (Nanchang, China) for their assistance. The present study was supported by The National Natural Science Foundation of China (grant no. 31460239) and by The Natural Science Foundation of Jiangxi Province (grant no. 20122BAB205058).

\section{References}

1. Isozaki T, Rabquer BJ, Ruth JH, Haines GK II and Koch AE: ADAM-10 Is Overexpressed in rheumatoid arthritis synovial tissue and mediates angiogenesis. Arthritis Rheum 65: 98-108, 2013.

2. Szabó-Taylora KÉ, Eggleton P, Turner CA, Faro ML, Tarr JM, Tóth S, Whiteman M, Haigh RC, Littlechild JA and Winyard PG: Lymphocytes from rheumatoid arthritis patients have elevated levels of intracellular peroxiredoxin 2 and a greater frequency of cells with exofacial peroxiredoxin 2, compared with healthy human lymphocytes. Int J Biochem Cell Biol 44: 1223-1231, 2012.

3. Stanford SM, Maestre MF, Campbell AM, Bartok B, Kiosses WB, Boyle DL, Arnett HA, Mustelin T, Firestein GS and Bottini N: Protein tyrosine phosphatase expression profile of rheumatoid arthritis fibroblast-like synoviocytes: A novel role of SH2 domain-containing phosphatase 2 as a modulator of invasion and survival. Arthritis Rheum 65: 1171-1180, 2013.

4. Garcia S, Liz M, Gómez-Reino JJ and Conde C: Akt activity protects rheumatoid synovial fibroblasts from Fas-induced apoptosis by inhibition of Bid cleavage. Arthritis Res Ther 12: R33, 2010.

5. Xu K, Xu P, Yao JF, Zhang YG, Hou WK and Lu SM: Reduced apoptosis correlates with enhanced autophagy in synovial tissues of rheumatoid arthritis. Inflamm Res 62: 229-237, 2013.

6. Korb A, Pavenstädt H and Pap T: Cell death in rheumatoid arthritis. Apoptosis 14: 447-454, 2009.

7. Lawlor KE, Nieuwenhuijze AV, Parker KL, Drake SF, Campbell IK, Smith SD, Vince JE, Strasser A and Wicks IP: Bcl-2 overexpression ameliorates immune complex-mediated arthritis by altering Fc $\gamma \mathrm{RIIb}$ expression and monocyte homeostasis. J Leukoc Biol 93: 585-597, 2013.

8. Bartok B and Firestein GS: Fibroblast-like synoviocytes: Key effector cells in rheumatoid arthritis. Immunol Rev 233: 233-255, 2010. 
9. Kim SK, Park KY, Yoon WC, Park SH, Park KK, Yoo DH and Choe JY: Melittin enhances apoptosis through suppression of IL-6/sIL-6R complex-induced NF- $\kappa$ B and STAT3 activation and Bcl-2 expression for human fibroblast-like synoviocytes in rheumatoid arthritis. Joint Bone Spine 78: 471-477, 2011.

10. Shu Q, Fu YY, Lu T and Yu YY: Study on anti-tumor effect of the Daphne odora var. Marginata's Extracts on SMMC-7721 and MCF-7 cells. Lishizhen Med Materia Med Res 9: 2149-2150, 2009.

11. Li H, Li WP, Liu X, Wang JP and Yang SJ: Experimental study of daphnetin and its derivatives influence on microcirculation of type 2 diabetic rats. Jilin Med 30: 2981-2983, 2010.

12. Yao R, Fu Y, Li S, Tu L, Zeng X and Kuang N: Regulatory effect of daphnetin, a coumarin extracted from Daphne odora, on the balance of Treg and Th17 in collagen-induced arthritis. Eur J Pharmacol 670: 286-294, 2011.

13. Zhang ZQ: The demethylation molecular mechanism and the effect of daphnetin on the proapoptotic genes in the collagen-induced arthritis rats synovial cells (unpublished PhD thesis). Nanchang University, 2012.

14. Ye C, Bhan AK, Deshpande V, Shankar P and Manjunath N: Silencing TNF- $\alpha$ in macrophages and dendritic cells for arthritis treatment. Scand J Rheumatol 42: 266-269, 2013.

15. Davis ME, Zuckerman JE, Choi CH, Seligan D, Tolcher A, Alabi CA, Yen Y, Heidel JD and Ribas A: Evidence of RNA in human from systemically administered siRNA Via targeted nanoparticles. Nature 464: 1067-1070, 2010.

16. Lan ZY, Bai XZ and Han XR: Tak1 siRNA impact on mmp99 and tinpl expression in synovial cells of patients with rheumatoid arthritis. J China Med Univ 41: 540-543, 2012

17. Kang EH, Kim DJ, Lee EY, Lee YJ, Lee EB and Song YW: Downregulation of heat shock protein 70 protects rheumatoid arthritis fibroblast-like synoviocytes from nitric oxide-induced apoptosis. Arthritis Res Ther 11: R130, 2009.

18. Toh ML, Gonzales G, Koenders MI, Tournadre A, Boyle D, Lubberts E, Zhou Y, Firestein GS, van den Berg WB and Miossec P: Role of Interleukin 17 in arthritis chronicity through survival of synoviocytes via regulation of synoviolin expression. PLoS One 5: e13416, 2010.

19. Livak KJ and Schmittgen TD: Analysis of relative gene expression data using real-time quantitative PCR and the 2(-Delta Delta C(T)) method. Methods 25: 402-408, 2001.

20. Chen YJ, Chang YT, Wang CB and Wu CY: The risk of cancer in patients with rheumatoid arthritis: A nationwide cohort study in Taiwan. Arthritis Rheum 63: 352-358, 2011

21. Perkins S, Cohen M, Rahme E and Bernasky S: Melanoma and rheumatoid arthritis (brief report). Clin Rheumatol 31: 1001-1003, 2012

22. Wang L, Wang CH, Jia JF, Ma XK, Li Y, Zhu HB, Tang H, Chen ZN and Zhu P: Contribution of Cyclophilin A to the regulation of inflammatory processes in rhuematiod arthritis. J Clin Immunol 30: 24-33, 2010

23. Yu P, Long L, Wang SY, Li R and Zhang XP: Expression and function of MiR-155 in fibroblasts of rheumatoid arthritis. Chin J Rheumatol 14: 460-463, 2010.

24. Guma M, Hammaker D, Topolewski K, Corr M, Boyle DL, Karin M and Firestein GS: Antiinflammatory functions of p38 in mouse models of rheumatoid arthritis: Advantage of targeting upstream kinases MKK-3 or MKK-6. Arthritis Rheum 64 $2887-2895,2012$

25. Mor A, Abramson SB and Pillinger MH: The fibroblast-like synovial cell in rheumatoid arthritis: A key player in inflammation and joint destruction. Clin Immunol 115: 118-128, 2005.
26. Huber LC, Distler O, Tarner I, Gay RE, Gay S and Pap T: Synovial fibroblasts: Key players in rheumatoid arthritis. Rheumatology (Oxford) 45: 669-675, 2006.

27. Fox DA, Gizinski A, Morgan R and Lundy SK: Cell-cell Interactions in rheumatoid arthritis synovium. Rheum Dis Clin North Am 36: 311-323, 2010.

28. Baier A, Meinekel I, Gay S and Pap T: Apoptosis in rheumatoid arthritis. Curt Opin Rheumatol 15: 274-279, 2003.

29. Liang SC, Ge GB, Liu HX, Zhang YY, Wang LM, Zhang JW, Yin L, Li W, Fang ZZ, Wu JJ, et al: Identification and Characterization of Human UDP-Glucuronosyltransferases responsible for the in vitro glucuronidation of daphnetin. Drug Metab Dispos 38: 973-980, 2010

30. Shu Q, Fu YY and Liu T: The study of active ingredients of Daphne odero as Daphne flava-I and Daphnetin application on SMMC-7721 and MCF-7 cells. Materia Med 20: 2149-2150, 2009.

31. Xu J, Fu YY, Huang BH, Zeng XP and Kuang NZ: The effect of Daphne odero extract anti-tumor in vitro and vivo. Chin J New Drugs 17: 2019-2026, 2008.

32. Huang BH, Fu YY and Xu J: Daphne Odora impact on immune function of mice with S180 tumor. Materia Med 19: 2376-2377, 2008.

33. Tu LN, Li S, Fu Y, Yao R, Zhang Z, Yang S, Zeng X and Kuang N: The therapeutic effects of daphnetin in collagen-induced arthritis involve its regulation of Th17 cells. Int Immunopharmacol 13: 417-423, 2012.

34. Dumesic PA, Natarajan P, Chen C, Drinnenberg IA, Schiller BJ, Thompson J, Moresco JJ, Yates JR III, BartelDP and Madhani HD: Stalled spliceosomes are a signal for RNAi-mediated genome defense. Cell 152: 957-968, 2013.

35. Tabach Y, Billi AC, Hayes GD, Newman MA, Zuk O, Gabel H, Kamath R, Yacoby K, Chapman B, Garcia SM, et al: Identification of small RNA pathway genes using patterns of phylogenetic conservation and divergence. Nature 493: 694-698, 2013.

36. Chi PL, Chen YW, Hsiao LD, Chen YL and Yang CM: Heme oxygenase 1 attenuates interleukin-1 $\beta$-induced cytosolic phospholipase A2 expression via a decrease in NADPH oxidase/reactive oxygen species/activator protein 1 activation in rheumatoid arthritis synovial fibroblasts. Arthritis Rheum 64: 2114-2125, 2012.

37. Park JS, Yang HN, Jeon SY, Woo DG, Kim MS and Park KH: The use of anti-COX2 siRNA coated onto PLGA nanoparticles loading dexamethasone in the treatment of rheumatoid arthritis. Biomaterials 33: 8600-8612, 2012.

38. Gao Wei, Feng Xin, Ren Li-Bing, et al: Expressions and significance of apoptosis-related factors Bcl-xl, Bcl-2 and Bax in synovial tissues of rats with rheumatoid athritis. Chin Gen Med 15: 2776-2779, 2012.

39. Ferdek PE, Gerasimenko JV, Peng S, Tepikin AV, Petersen $\mathrm{OH}$ and Gerasimenko OV: A novel role for $\mathrm{Bcl}-2$ in regulation of cellular calcium extrusion. Curr Biol 22: 1241-1246, 2012.

40. Li GH, Wei H, LV SQ, JI H and Wang DL: Knockdown of STAT3 expression by RNAi suppresses growth and induces apoptosis and differentiation in glioblastoma stem cells. Int J Oncol 37: 103-110, 2010.

41. Lee SY, Kwok SK, Son HJ, Ryu JG, Kim EK, Oh HJ, Cho ML, Ju JH, Park SH and Kim HY: IL-17-mediated Bcl-2 expression regulates survival of fibroblast like synoviocytes in rheumatoid arthritis through STAT3 activation. Arthritis Res Ther 15: R31, 2013. 